\title{
ARCTIC OSCILLATION IMPACT ON THERMAL REGIME IN THE EASTERN PART OF THE BALTIC REGION
}

\section{Gečaite, A.I. Pogoreltsev, A.I. Ugryumov}

Russian State Hydrometeorological University, Saint Petersburg, Russia gecaite.indre@gmail.com

The paper presents statistical estimations of Arctic Oscillation (AO) impact on air temperature regime in the eastern part of the Baltic region. The region is characterized by high inter-annual and inter-seasonal variability. It is important to note that in the region of global warming extremely low winter temperatures can be observed on the European territory of Russia. AO is one of the large-scale global patterns of atmospheric circulation closely associated with weather variability in northern Europe. AO anomalies occur in the upper atmosphere (stratosphere) and only then are transferred to tropospheric lower layers. The anomalies can persist over a long period of time (up to two months); so they can serve as precursors in long-range weather forecasts. In turn, changes in stratospheric polar vortex and sudden stratospheric warmings can be related to geomagnetic activity. Perhaps geomagnetic activity influences the meridional temperature gradient and then changes the structure of the stratospheric zonal wind. These changes have an effect on the tropospheric circulation. The stratosphere-troposphere coupling takes place during winter months. Therefore, the paper deals with extremely cold winter anomalies in the eastern part of the Baltic Sea region. At the same time, we examine atmospheric circulation peculiarities associated with AO phase change. We analyze data for 1951-2014.

Keywords: Arctic Oscillation, polar vortex, extremely cold months, Eastern Europe, atmospheric circulation types.

\section{INTRODUCTION}

In the eastern part of the Baltic region, the weather during cold seasons is characterized by high inter-annual and inter-seasonal variability. The cause for this is the geographic location of the region through which various air masses travel. Not far from the Baltic region is the Arctic that produces cold air masses. The Atlantic Ocean supplies this region with wet and warm air masses. Extremely cold continental air masses come from the east, from Siberia, Asia.

The main global atmospheric circulation patterns influencing weather conditions both in northern Europe and in the region considered are the North Atlantic Oscillation (NAO) and the Arctic Oscillation 
(AO). They regulate the intensity of cyclonic and anticyclonic activity and thus advections of diverse air masses. This relationship is often estimated using catalogs of atmospheric circulation types because a certain atmospheric circulation type can bring about the formation of extreme weather conditions. These catalogs are utilized to assess variability of weather conditions (or climate) in accordance with previously established atmospheric circulation types. These types are most frequently selected based on the location of fronts, pressure patterns in a given region (position of hollows and ridges on synoptic charts) [Hoy et al., 2013], and tracks of cyclones and anticyclones [Dzerdzeyevsky, 1975].

The Arctic Oscillation is described by changes of the first empirical orthogonal function of pressure at sea level in the Northern Hemisphere $\left(20-90^{\circ} \mathrm{N}\right)$ in winter. One pressure center is in the Arctic; the other, between $37^{\circ}$ and $45^{\circ} \mathrm{N}$ [John et al., 2008]. There are two AO phases - negative and positive - that have different effects on weather conditions in the Northern Hemisphere.

Figure 1 presents a scheme of a polar vortex and its impact on weather conditions at its diverse intensity [John et al., 2008]. The AO index is negative with relatively high pressure over the North pole and with low one over middle latitudes (approximately over $45^{\circ} \mathrm{N}$ ). At the negative $\mathrm{AO}$ index, the vortex around the Arctic weakens, thus allowing cold air to penetrate into both central and southern regions of Europe, Asia, and North America [Hosansky, 2003]. When the AO index is positive, air pressure is distributed inversely [Jovanovic et al., 2008]. During this phase, high pressure at middle latitudes drives the west-east air-mass transport and jet stream father north [Cohen, 2011]. It brings warm and moist ocean air to Europe and North America. In the positive AO phase, cold Arctic air does not extend so far to the south as it would in the negative AO phase - the strong west-east airflow transport keeps cold air locked in Arctic latitudes.

Notice that there is a close relation between stratospheric and tropospheric processes, specifically between the stratospheric polar vortex intensity and the surface AO phase. Many authors attribute this to vertical propagation of planetary waves that, emerging in the troposphere, extend to the stratosphere, interacting there with the mean flow [Mordvinov et al., 2007b; Kulyamin, 2014, Dymnikov].

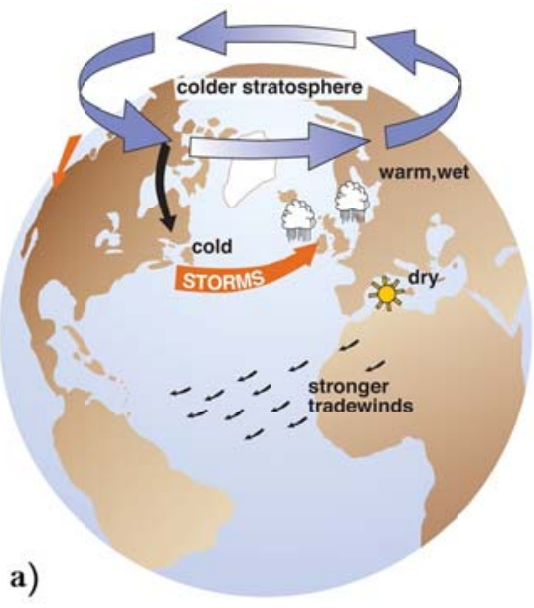

a

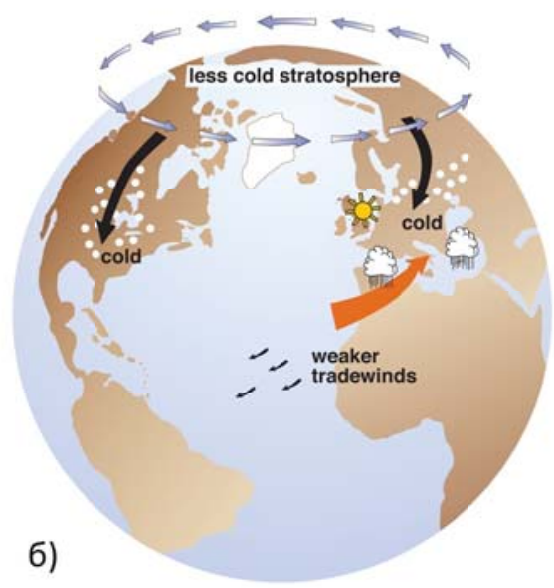

$b$

Figure 1. Positive (a) and negative (b) phases of the Arctic Oscillation. The influence of AO phase on winter weather in the Northern Hemisphere [Stricherz, 2001] 
Unfortunately, the processes that influence the formation of a particular AO phase are still underexplored. There are different hypotheses being discussed; especially notable among them is an increase in greenhouse gas emission and a decrease in Arctic glaciers [Stricherz, 2001], a variation in stratospheric water vapor [Solomon et al., 2010], a change in stratospheric ozone concentration [Wallace, Thompson, 2001], and sudden stratospheric warmings [Cohen, 2011; Vargin et al., 2015]. It is important to note that variations in solar and geomagnetic activity can cause a change in the phase of NAO (and accordingly AO) responsible for the interlatitude heat transfer in the atmosphere and ocean [Zherebtsov et al., 2008].

Obviously, AO and NAO explain similar variations in pressure distribution; the only difference is that NAO is a regional tropospheric mode, whereas AO represents air pressure variability in the entire Northern Hemisphere. It has been established that AO anomalies most often emerge in the stratosphere and only then are transferred to the troposphere [Baldwin, Dunkerton, 1999]. At the same time, the spatial pattern of correlations of inter-annual geomagnetic activity variations during winter with pressure and temperature variations in the troposphere and stratosphere of the Northern Hemisphere closely resembles the AO pattern. This explains the complex geographical dependence of multiple atmospheric effects of geomagnetic activity. This is likely responsible for the enhanced response of atmospheric circulation in the region of winter oceanic centers of action with the most pronounced AO [Mordvinov et al., 2007].

It is significant that until the end of 1960s the level of geomagnetic activity, AO and NAO intensities simultaneously decreased. Then the indices increased, reaching maximum values during the winters of 1989/90 and 1992/93, and decreased by the beginning of the first decade of the XXIst century [Mordvinov et al., 2007a]. In winter seasons with predominant positive AO phase there tends to be lower pressure over the Arctic and positive temperature anomalies in northern Eurasia and over much of the USA. Thus, we have firm grounds for analyzing possible AO effects on winter weather conditions in the Baltic region.

The purpose of this paper is to statistically estimate the Arctic Oscillation impact on air temperature regime and atmospheric circulation in the eastern part of the Baltic region.

\section{METHOD}

In the paper, we analyze cold winters over a period 1951-2014 in the eastern part of the Baltic region, i.e. on the territory bounded by $54-62^{\circ} \mathrm{N}$ and $20-33^{\circ} \mathrm{E}$ (Figure 2). Calculations are done from data with a resolution of $0.5^{\circ}$. Results were obtained from data on monthly and daily mean air temperature (CPC GHCN/CAMS t2m analysis (land)) at each point of the network (106 points in total) from the database of the European Climate Assessment and Dataset KNMI Climate Explorer [http://eca.knmi.nl]. Monthly mean values of air temperature at every point were utilized to calculate normalized temperature anomalies (1) employed then to identify extremely cold and warm winters for 1951-2014:

$$
Z=\frac{(x-\bar{x})}{\sigma},
$$

where $\bar{x}$ is the multiyear monthly mean surface air temperature; $x$ is a mean temperature for a given month and year; $\sigma$ is an rms temperature deviation. 


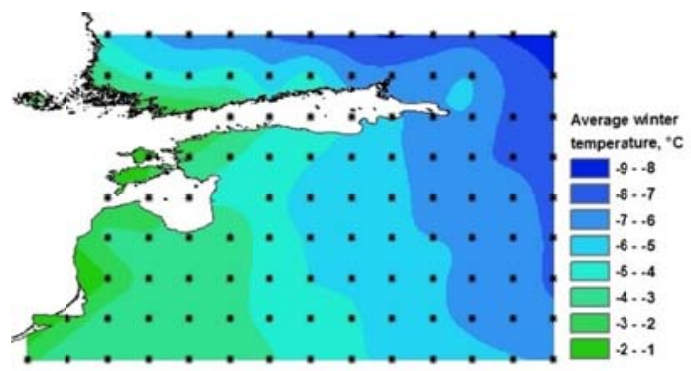

Figure 2. Air temperature distribution over the territory of interest in 1951-2014

The AO influence on temperature was examined by comparing anomalous cooling with atmospheric circulation types. They were identified by a computer-aided scheme [Jenkinson, Collison, 1977] the main factors in which are geostrophic wind and airflow vorticity (Table 1) [Post et al., 20012; Chen, 2000]. We calculated these factors from data on daily mean sea-level pressure taken from the NCEP/NCAR database for 16 points in $50-70^{\circ} \mathrm{N}$ and $10-40^{\circ} \mathrm{E}$.

We have selected 27 atmospheric circulation types grouped then into generalized types (eight types according to airflow direction and two types according to vorticity)

Daily and monthly mean AO indices were acquired from the database of the NOAA Climate Prediction Center [http://www.cpc.ncep.noaa.gov]. The data were visualized by the geographic information system software ArcMap 10.0.

\section{RESULTS}

Temperature distribution across this region greatly depends on the distance from the Baltic Sea that extends its influence for 30-100 km from the shore. Nearby the shore in winter there are warmer weather conditions and increasing temperature gradient. The mean air temperature in December-February 19512014 varied from $-1.7^{\circ} \mathrm{C}$ in the west of the region to $-8.1{ }^{\circ} \mathrm{C}$ in the northeast (Figure 2). The mean winter air temperature in the region considered is $-5.2^{\circ} \mathrm{C}$. On average, the temperature drops below zero on November 18 and again becomes positive on March 27; the most minimum temperatures are fixed in February (on February 11, it is approximately $-7.9^{\circ} \mathrm{C}$ ). But in some years, the air temperature strongly deviates from the long-term climatic norm (about 2-3 times).

Table 1. Circulation types defined by airflow direction, estimated general vorticity $(W)$, and its comparison to the threshold vorticity $(F)^{*}$

\begin{tabular}{|l|l|}
\hline \multicolumn{1}{|c|}{ Description } & \multicolumn{1}{c|}{ Interpretation } \\
\hline Airflow direction (N, NE, E, SE, S, SW, W, NW) & $|W|<F$ \\
\hline Anticyclonic vorticity (A) & When $|W|>2 F$ and $W<0$ \\
\hline Cyclonic vorticity (C) & When $|W|>2 F$ and $W>0$ \\
\hline Mixed type (airflow direction + vorticity) & When $F<|W|<2 F$ \\
\hline Unclassified type (U) & When $W<$ annual mean $W, F<$ annual mean $F$ \\
\hline
\end{tabular}

$* W$ and $F$ being compared, a decision is made on the circulation type. 
Table 2. Criteria of classification of winter months by the degree of temperature anomaly in the eastern part of the Baltic region

\begin{tabular}{|c|c|c|c|c|c|c|c|}
\hline $\begin{array}{c}\text { Month } \\
\text { characteristic }\end{array}$ & $\begin{array}{c}\text { Extremely } \\
\text { cold }\end{array}$ & $\begin{array}{c}\text { Abnormally } \\
\text { cold }\end{array}$ & Cold & Norm & Warm & $\begin{array}{c}\text { Abnormally } \\
\text { warm }\end{array}$ & $\begin{array}{c}\text { Extremely } \\
\text { warm }\end{array}$ \\
\hline Limits of $z$ & $z<-2.11$ & $-2.1<z<-1.41$ & $-1.4<z<-0.71$ & $-0.7<z<0.7$ & $0.71<z<1.4$ & $1.41<z<2.1$ & $z>2.11$ \\
\cline { 2 - 7 } Category & -3 & -2 & -1 & 0 & +1 & +2 \\
\hline
\end{tabular}

From monthly mean air temperature values at each point of the network we calculated normalized temperature anomalies $(z)$ and singled out particularly cold and warm months for a period from 1951 to 2014. Thermal winter conditions were determined from the classification proposed by K. Pfister [Przybylak et al., 2005; Maheras et al., 1999]. It gives seven criteria of thermal winter conditions - from extremely cold to extremely warm ones (Table 2). We have identified 24 cold, 17 abnormally cold, and 4 extremely cold months. For the period, we have also revealed 39 warm, 8 abnormally warm, and 1 extremely warm winter months.

We have established that anomalies of monthly mean air temperature for $-1,-2$, and -3 categories most often cover no less than $50 \%$ of the territory. Such anomalous weather conditions exist under changes of the large-scale atmospheric circulation in the Northern Hemisphere. In this period, extremely cold months were (year/month) 1978/12, 1987/01, 1956/02, 1985/02; abnormally cold months, 1955/12, 1967/12, 1969/12, 2001/12, 2002/12, 2010/12, 1963/01, 1966/01, 1967/01, 1968/01, 1969/01, 1972/01, 1985/01, 2010/01, 1954/01, 1966/02, 1986/02 (Figure $3 a, b$ ).

Next consider the time dependence of the normalized winter temperature anomalies and the AO index from 1950 to 2014. Figure 3, $a, b$ clearly shows a sufficiently high direct correlation between the time series: to positive AO index generally correspond positive temperature anomalies; to low AO index, negative ones. The correlation between the mean winter air temperature in the entire region and the AO index $r=0.71$ (at $99 \%$ statistical significance). Closer correlations were found for the continental part of the territory considered. It can be observed (Figure 3, $a, b$ ) that in the second half of the period abnormally cold months are much rarely registered, particularly in 1988-2008. This is also clearly represented by the $\mathrm{AO}$ index variability in this time interval. It has been discovered that in this region the Arctic Oscillation affects snow cover characteristics too [Rimkus et al., 2014].

The results showing that there is a close correlation between the large-scale atmospheric circulation and air temperature variations allow us to estimate how fast the temperature regime responds to the AO phase change. To do this, we analyzed the time variation of daily data on temperature anomalies and AO index for 17 abnormally cold months in 1951-2014. As an example, we present variations of these parameters in December 1955, January 1968, January-February 1986, and December 2010 (Figure 4, $a-d$ ). 


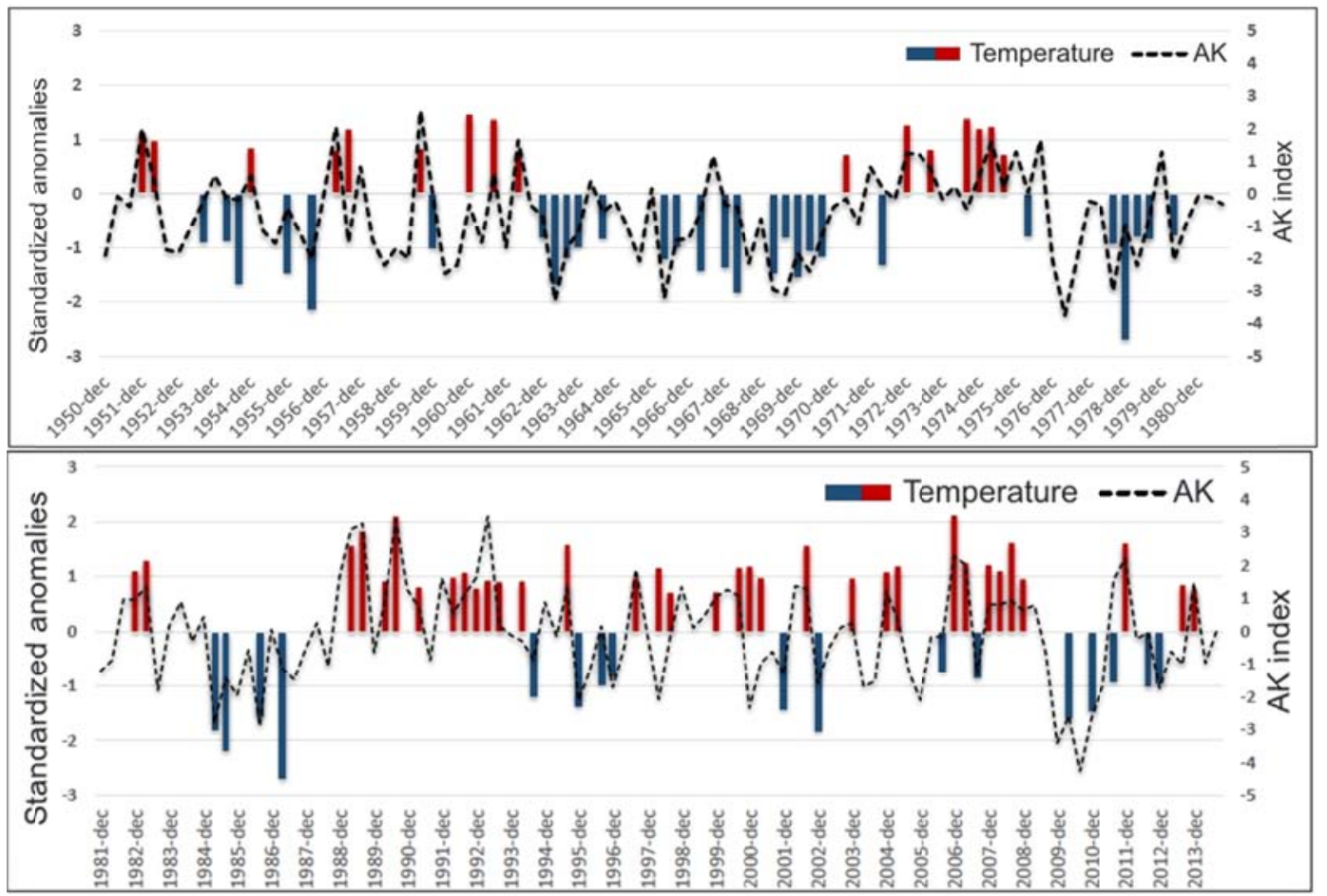

Figure. 3. Particularly cold and warm winter months and values of the AO index in 1951-1981 (a) and 1981$2014(b)$
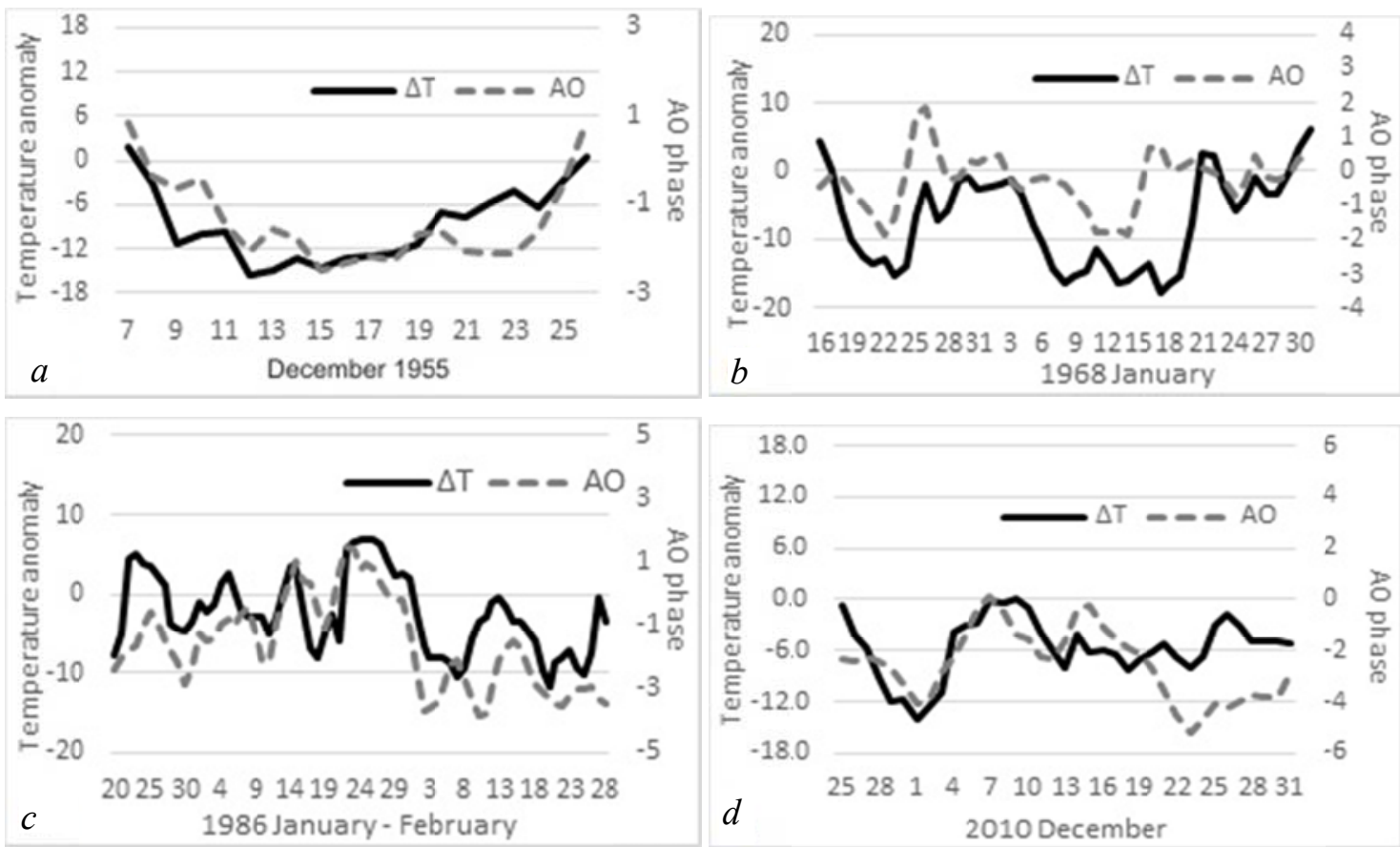

Figure 4. Time dependence of the AO index and air temperature in the eastern part of the Baltic region

The analysis revealed a similarity between the AO time variation and the air temperature. It was also found that with the time series of temperature being shifted relative to the AO index from 2 to 6 days, variations of the AO index and air temperature anomaly become almost synchronous. This proves that air 
temperature changes rapidly due to atmospheric circulation changes with the $\mathrm{AO}$ phase - the average reaction time is from 2 to 6 days.

To estimate atmospheric circulation peculiarities in abnormally cold winter months, we statistically analyzed atmospheric circulation types. It was established that the abnormally cold winter months were characterized by predominant anticyclonic circulation ( $41 \%$ of all days) with a frequent airflow transport from the eastern quarter of the horizon $-32 \%$ (merely east transport $-13 \%$, south-east $-13 \%$, and north-east - 6\%). Particularly notable are January 1961, December 1978, and January 2010 with negative temperature anomalies being driven by other circulation conditions.

Notice the relation of the particularly cold months in this region with solar and geomagnetic activity: cold months were most often encountered during low solar activity, whereas one of the warmest winters (the winter of 1989) coincided with maximum geomagnetic activity and high AO index. Results of other studies agree with the statistical relations we found. Mordvinov et al. [Mordvinov et al., 2007a] has established that the correlation coefficient between geomagnetic activity and AO index $r=0.32$.

\section{CONCLUSION}

We have found a relation between the $\mathrm{AO}$ phase and the air temperature in the eastern part of the Baltic region (the correlation coefficient $r=0.71$ ). The analysis of daily data revealed that in abnormally cold winter months AO phase changes caused relatively fast temperature response in this region. This occurred due to atmospheric circulation restructuring: the temperature field responded 2-6 days after the AO index had changed. During cold periods with the negative AO index there prevailed anticyclonic circulation and eastward airflow transport. This is generally uncharacteristic of this region.

The study was supported by the Russian Science Foundation (grant No. 14-17-00685).

\section{REFERENCES}

Baldwin M.P., Dunkerton T.J. Propagation of the Arctic Oscillation from the stratosphere to the troposphere. $J$. Geophys. Res. 1999, vol. 104, no. D24, pp. 937-946.

Chen D. A monthly circulation climatology for Sweden and its application to a winter temperature case study. Intern. J. Climatology. 2000. N 20. P. 1067-1076.

Cohen J. Eurasian snow cover variability and links with stratosphere-troposphere coupling and their potential use in seasonal to decadal climate predictions. Climate Test Bed Joint Seminar Series. NCEP, Camp Springs, Maryland. 2011.

Dzerdzeevsky B.L. Obshchaya tsirkulyatsiya atmosfery i klimat [Total Atmospheric Circulation and Climate]. Moscow, Nauka Publ., 1975, 228 p. (in Russian).

Hosansky D. The Arctic Oscillation: A key to this winter's cold — and a warmer planet. NCAR News Release. 2003. URL: www.ucar.edu (accessed April 8, 2012).

Hoy A., Jaagus J., Sepp M., Matschullat J. Spatial response of two European atmospheric circulation classifications (data 1901-2010). Theoretical and Applied Climatology. 2013, no. 112, pp. 73-88. DOI: http://dx.doi.org/10.2112/ JCOASTRES-D-10-00157.1. 
Jenkinson A.F., Collison F.P. An initial climatology of gales over the North Sea. Synoptic Climatology Branch Memorandum no. 62. Bracknell, Meteorological Office, 1977, p. 18.

John N., Scott S., Suim T., Wittoya K. North Atlantic Oscillation (NAO) / Arctic Oscillation (AO). Department of Meteorology SJSU. 2008. URL: http://www.met.sjsu.edu (accessed November 11, 2010).

Jovanovic G., Reljin I., Reljin B. The influence of Arctic and North Atlantic Oscillation on precipitation regime in Serbia. IOP Conf. Series: Earth and Environmental Science. 2008, vol. 4, no. 1, 012025. DOI: http://dx.doi.org/ 10.1088/1755-1307/4/1/012025.

Kulyamin D.V., Dymnikov V.P. Modeling of the total circulation of the troposphere-stratosphere-mesosphere including the ionospheric D layer. Geliogeofizicheskie issledovaniya [Heliogeophysical Research]. 2014, iss. 10, pp. 5-44 (in Russian).

Maheras P., Xoplaki E., Davies T., Martin-Vide J., Bariendos M., Alcoforado M.J. Warm and cold monthly anomalies across the Mediterranean Basin and their relationship with circulation; 1860-1990. Intern. J. Climatology. 1999, no. 19, pp. 1697-1715.

Mordvinov V.I., Ivanova A.S., Devyatova E.V. Arctic Oscillation and troposphere-stratosphere interactions. Solnechno-zemnaya fizika [Solar-Terrestrial Physics]. 2007b, iss. 10, pp. 106-112 (in Russian).

Mordvinov V.I., Ivanova A.S., Devyatova E.V. Geomagnetic activity and the total atmospheric circulation. Solnechno-zemnaya fizika [Solar-Terrestrial Physics]. 2007a, iss. 10, pp. 16-24 (in Russian).

Post P., Truija V., Tuulik J. Circulation weather types and their influence on temperature and precipitation in Estonia. Boreal Environment Research. 2002, no. 7, pp. 281-289.

Przybylak R., Majorowicz J., Wojcik G., Zielski A., Chorazyczewski W., Marciniak K., Nowosad W., Olinski P., Syta K. Temperature changes in Poland from the $16^{\text {th }}$ to the $20^{\text {th }}$ centuries. Intern. J. Climatology. 2005, no. 25, pp. 773-791.

Rimkus E., Kazys J., Butkute S., Gecaite I. Snow cover variability in Lithuania over the last 50 years and its relationship with large-scale atmospheric circulation. Boreal Environment research. 2014, no. 19, pp. 337-351.

Solomon S., Rosenlof K., Portmann R., John D., Sean D., Sanford T., Plattner G.K. Contributions of stratospheric water vapor to decadal changes in the rate of global warming. Science. 2010, vol. 327, no. 5970, pp. 1219-1223. DOI: 10.1126/science.1182488.

Stricherz V. UW scientists say Arctic Oscillation might carry evidence of global warming // University of Washington. 2001. URL:http://www.washington.edu/news/2001/06/01/uw-scientists-say-arctic-oscillation-might-carry-evidence-ofglobal-warming/ (accessed September 10, 2015).

Vargin P.N., Volodin E.M., Karpechko A.Yu., Pogorel'tsev A.I. On stratosphere-troposphere interactions. Vestnik RAN [Herald of the Russian Academy of Sciences]. 2015, vol. 85, no. 1, pp. 39-46 (in Russian).

Zherebtsov G.A., Kovalenko V.A., Molodykh S.I., Rubtsova O.A. Solar activity and dynamic processes in the atmosphere and World Ocean heat content. Solnechno-zemnaya fizika [Solar-Terrestrial Physics]. 2008, iss. 12, vol. 2, pp. 268-271 (in Russian).

URL: http://eca.knmi.nl (accessed August 18, 2015).

URL: http://www.cpc.ncep.noaa.gov (accessed August 18, 2015).

The article is based on materials of the XIV $V^{\text {th }}$ Young Scientists' Conference "Interaction of fields and radiation with matter" of Baikal Young Scientists' International School on Fundamental Physics (September 14-18, 2015, Irkutsk, Russia) 